\title{
RESFRIAMENTO DA COBERTURA DE AVIÁRIOS E SEUS EFEITOS NA MORTALIDADE E NOS ÍNDICES DE CONFORTO TÉRMICO
}

\author{
MACHADO, Neiton Silva ${ }^{1}$ \\ TINÔCO, Ilda de Fátima Ferreira ${ }^{2}$ \\ ZOLNIER, Sérgio ${ }^{2}$ \\ MOGAMI, Cristina Akemi ${ }^{3}$ \\ DAMASCENO, Flávio Alves² \\ ZEVIANI, Walmes Marques ${ }^{4}$
}

RESUMO: A alta incidência de radiação solar sobre a cobertura das instalações avícolas é um dos principais fatores que causam estresse térmico nos animais. Desta maneira, objetivou-se, com o presente trabalho, dimensionar e avaliar um sistema de resfriamento da cobertura de galpões comerciais para criação de frangos de corte, com vista ao uso de água de chuva, no município de Rio Verde (GO). Durante o dimensionamento do sistema, foi considerado o resfriamento da cobertura a partir da aspersão de água armazenada durante o período chuvoso, sendo denominado de Sistema de Resfriamento de Cobertura Sustentável (SRCS). Para avaliação do sistema SRCS, foram utilizados seis galpões comerciais, os quais foram climatizados com ventilação forçada em modo túnel (pressão negativa) e sistema de resfriamento por nebulização interna. Em três destes galpões foi implementado o resfriamento adicional da cobertura (SRCS) e nas três instalações restantes foi utilizado apenas o sistema convencional de climatização (SCC) especificado anteriormente. Durante o período compreendido entre o $21^{\circ}$ e o $42^{\circ}$ dia de vidas das aves, foram quantificados três índices de conforto térmico (índice de temperatura de globo negro e umidade, carga térmica de radiação e entalpia específica do ar) e a mortalidade dos animais. Os resultados indicaram que o resfriamento adicional da cobertura reduziu, significativamente, a mortalidade das aves na última semana de vida, fato que foi considerado como uma das maiores vantagens do sistema. Com os resultados obtidos foi ajustado os parâmetros de um modelo estatístico exponencial que permite estimar a mortalidade dos animais a partir do $21^{\circ}$ dia de vida, para os sistemas SRCS e SCC, em função da idade das aves e entalpia específica do ar.

Palavras-chave: Frangos de corte. Bem estar animal. Sistema de resfriamento adiabático.

\section{ROOF COOLING OF POULTRY HOUSES AND ITS EFFECT ON MORTALITY AND THERMAL COMFORT INDEXES}

SUMMARY: The high incidence of solar radiation on poultry house roof is one of the main factors that causes thermal stress on the animals. In this way, the objective of this work was to design and evaluate a cooling system that was implemented on the roof of commercial poultry houses, located in Rio Verde (GO). During the system design, it was considered the roof cooling by sprinkling water stored during the climatic rainy period, which was denoted by sustainable roof cooling system (SRCS). To evaluate the SRCS system, six commercial poultry houses were climatized with a tunnel ventilation system (negative pressure) and an internal fogging system. In three houses, additional cooling was implemented by sprinking water on the roof (SRCS) and only the conventional climatized system (CCS) was used in the three remaining houses. During the period from 21 to 42 days after the birds were hatched, three thermal comfort indexes (index of black globe temperature and humidity, radiant heat load and air specific enthalpy) and animal mortality were evaluated. The results indicated that the additional roof cooling significantly reduced bird mortality in the last week of the growth period, a fact that was considered as one of the main advantages of the system. With the obtained results, parameters of an exponential statistical model were adjusted as well, which allows to estimate animal mortality after 21 days of age, for the SRCS and CCS systems, as a function of age and air specific enthalpy.

Keywords: Broiler. Animal welfare. Adiabatic cooling system.

\footnotetext{
${ }^{1}$ UNIVASF/CEAGRO - Fundação Universidade Federal do Vale do São Francisco/Colegiado de Engenharia Agronômica

${ }^{2}$ UFV/DEA - Universidade Federal de Viçosa/Departamento de Engenharia Agrícola

${ }^{3}$ Instituto Federal de Educação, Ciência e Tecnologia Sertão Pernambucano/Zona Rural

${ }^{4}$ UFPR - Universidade Federal do Paraná / Departamento de Estatística
} 


\section{INTRODUÇÃO}

A produção mundial de carne de frango, segundo o Departamento de Agricultura dos Estados Unidos, conhecido internacionalmente pela sigla USDA, registrou um aumento de 4,0\% em 2009, passando de 79,3 para 81,7 milhões de toneladas. Embora a produção de carne de frango nos Estados Unidos registrou uma expansão de $19 \%$ desde 2000, a produção de carne de frango no Brasil teve um crescimento de $90 \%$, resultado que manteve o país entre os maiores produtores mundiais, ficando atrás somente da produção norte americana e chinesa (USDA, 2010). Fatores como a globalização, aumento da concorrência, desaceleração da economia mundial, demanda por produtos de melhor qualidade e mais saudáveis, têm levado os avicultores a procurar novas tecnologias para alcançar maior produtividade com menores custos, considerando o bem-estar dos animais.

Apesar do crescimento da avicultura, verifica-se que, em climas tropicais e subtropicais, como ocorre no Brasil, os altos valores de temperatura do ar e umidade relativa, principalmente no verão, geram condições de desconforto térmico quase permanente às aves, dificultando seu desempenho produtivo e constituindo um dos principais problemas que afetam a sua criação. Como estratégia para adequar o ambiente térmico no interior das instalações às exigências de conforto térmico das aves, a climatização é uma saída eficiente. Desse modo, são considerados sistemas de climatização, aqueles que utilizam equipamentos de ventilação, nebulização, painéis de resfriamento adiabático e aspersão de água sobre a cobertura. Proporcionar o conforto térmico no interior dessas instalações avícolas, devido às condições climáticas inadequadas, torna-se um desafio para os profissionais da área de construções rurais, uma vez que situações extremas de calor afetam consideravelmente a produção (NÄ̈̈S et al., 2001).

A alta incidência de radiação solar sobre a cobertura das instalações avícolas é um dos principais causadores do estresse térmico nos aviários. O grande desafio para avicultura no Brasil é o desenvolvimento de tecnologias de baixo custo, que proporcionem às aves condições ambientais favoráveis para que estas possam expressar todo o seu potencial genético, uma vez que materiais isolantes são relativamente caros.

Desse modo, diversos estudos foram conduzidos com o objetivo de se avaliar os benefícios proporcionados por sistemas de climatização em instalações avícolas, visando o entendimento do problema e a busca por soluções em condições de campo (SIMMONS; LOTT, 1996; PERDOMO, 1998; SARTOR, et al 2001, TINÔCO et al., 2002; ABREU et al., 2007; FERREIRA JUNIOR et al., 2009; SEO et al., 2009). No entanto, a aspersão de água sobre a cobertura tem sido utilizada somente nos últimos anos, como forma de se obter, eficientemente, a redução do impacto do estresse térmico no interior das instalações. Esta técnica implica em baixos custos no desenvolvimento e adaptação de projetos de climatização já implementados, permitindo também estudar aspectos no desempenho produtivo e respostas fisiológicas das aves alojadas.

Moraes et al (1999), realizaram um experimento com modelos reduzidos de galpões avícolas, usando-se telhas de cimento-amianto como testemunha e associações de forro de polietileno, aspersão de água sobre a cobertura, dupla lâmina reflexiva de alumínio sob a cobertura, pintura branca na face superior da telha, poliuretano na face superior da cobertura, poliuretano na face inferior, com o objetivo de se estudar o conforto térmico no interior dos modelos, através do Índice de Temperatura de Globo e Umidade (ITGU) e da Carga Térmica de Radiação (CTR). Os autores concluíram que todos os tratamentos possibilitaram redução nos valores de ITGU, sendo o mais eficiente a aspersão, seguido do forro de polietileno.

Nesse sentido, a aspersão de água diretamente sobre a cobertura, nas horas mais quentes do dia, reduz a temperatura do telhado, tanto por condução quanto por evaporação, melhorando a eficiência de

Nucleus, v.9, n.2, out.2012 
resfriamento interno do galpão proporcionando maior conforto térmico às aves. Outro ponto importante envolvido no processo de aspersão de água de chuva sobre a cobertura é a questão ambiental e de sustentabilidade, pois é uma tecnologia que permite a conservação e reaproveitamento da água durante os períodos de acionamento do sistema. Sendo a água um recurso natural limitado, dotado de valor econômico, é extremamente importante o uso eficiente.

Diante do exposto, o objetivo deste trabalho foi planejar, implantar e avaliar um sistema de resfriamento térmico, por meio da aspersão de água proveniente da chuva sobre coberturas de aço galvanizado, em instalações comerciais para a produção de frangos de corte, visando identificar seus efeitos sobre os índices de conforto térmico e a mortalidade dos animais.

\section{MATERIAL E MÉTODOS}

A presente pesquisa foi realizada em duas etapas:

a) primeiramente, desenvolveu-se um projeto de aspersão de água sobre a cobertura de galpões comerciais de frango de corte, com aproveitamento da água captada durante o período climaticamente chuvoso (novembro a março), para ser utilizada posteriormente no período seco (maio a setembro), denominado de Sistema de Resfriamento de Cobertura Sustentável - SRCS; e

b) Na segunda etapa, avaliou-se a eficiência do sistema SRCS, com o intuito de promover o conforto térmico ambiente e melhoria do bem-estar animal. $\mathrm{O}$ índice de conforto proporcionado pelo sistema foi avaliado indiretamente pela taxa de mortalidade das aves.

\section{Caracterização dos galpões avícolas}

$\mathrm{O}$ experimento foi realizado no município de Rio Verde - $\mathrm{GO}\left(17^{\circ} 55^{\prime} \mathrm{S}\right.$ de latitude; $50^{\circ} 55^{\prime} \mathrm{O}$ de longitude; e $753 \mathrm{~m}$ de altitude), entre os meses de janeiro e fevereiro, em seis galpões comerciais para a criação de frangos de corte, os quais estavam equipados com ventilação em modo túnel (pressão negativa) e sistema de resfriamento por nebulização interna.

Três galpões foram equipados com ventilação em modo túnel (pressão negativa) e nebulização interna, mais um sistema adicional de resfriamento evaporativo por aspersão na cobertura, cujo conjunto de climatização será denominado neste artigo de sistema SRCS. No que se refere apenas à aspersão de água sobre a cobertura, o sistema era composto de uma motobomba (potência de 1,5 CV e 81,5\% de rendimento) e microaspersores (bocal de $1,2 \mathrm{~mm}$ de diâmetro e vazão média de $88 \mathrm{~L} \mathrm{~h}^{-1}$ ), que foram distribuídos ao longo da cumeeira em espaços equidistantes de $6,0 \mathrm{~m}$. O sistema de aspersão era controlado por meio do sinal elétrico proveniente de um sensor de temperatura instalado a 39 metros de distância dos exaustores. O sistema era acionado diariamente, entre 10:30 h às 19:00 h, quando a temperatura do ar interna nos aviários ficava acima de $31^{\circ} \mathrm{C}, 28^{\circ} \mathrm{C}$ e $26^{\circ} \mathrm{C}$, correspondendo aos períodos entre a $4^{\mathrm{a}}, 5^{\mathrm{a}}$ e $6^{\mathrm{a}}$ semanas de vidas das aves, respectivamente.

Além dos galpões dotados de sistema completo de climatização, incluindo a aspersão de água na cobertura (SRCS), foram também utilizados três galpões equipados apenas com ventilação em modo túnel (pressão negativa) e com sistema de resfriamento por nebulização interna, o qual será denominado de sistema convencional de climatização (SCC).

Neste experimento, todos os galpões possuíam dimensões de $125 \mathrm{~m}$ de comprimento, 12,8 $\mathrm{m}$ de largura e $3 \mathrm{~m}$ de pé-direito. A cobertura era constituída de telhas de aço galvanizado sem pintura, apresentando espessura de $1 \mathrm{~mm}$, com $0,5 \mathrm{~m}$ de beiral e $25 \%$ de inclinação. As alvenarias foram construídas com tijolo furado e as muretas laterais tinham $0,25 \mathrm{~m}$ de altura, sobre a qual foi instalada uma

Nucleus, v.9, n.2, out.2012 
tela de arame para fechamento lateral e revestida com cortinas plásticas na cor amarela. O piso era de terra batida, sobre o qual foi colocado uma cama de maravalha, três linhas de comedouros automáticos e quatro linhas de bebedouros tipo nipple. Os galpões, orientados na direção leste-oeste, possuíam sete exaustores (motor de 1 cv e 76,5\% de rendimento) e eram circundados por vegetação de Sibipiruna (Caesalpinia peltophoroides) e Eucalipto (Eucalyptus globulus).Em cada galpão, foram alojados 22.700 frangos de corte, da linhagem Cobb, com densidade de 14 aves $\mathrm{m}^{-2}$. O manejo dos animais foi idêntico em todos os galpões.

\section{Dimensionamento do Sistema de Resfriamento de Cobertura Sustentável ( $\underline{\text { SRCS }}$ )}

Para o dimensionamento do Sistema de Resfriamento de Cobertura Sustentável (SRCS), levou-se em consideração, primeiramente, as dimensões de um galpão convencional para criação de frangos de corte (125 m de comprimento x $12 \mathrm{~m}$ de largura). Desse modo, foi caracterizada a área superficial de captação de precipitação pluvial da cobertura, resultando em $1.765 \mathrm{~m}^{2}$ por instalação. No entanto, nos cálculos de captação, foram considerados dois galpões porque na maioria das vezes o sistema de alimentação destes galpões é interligado por um único silo aéreo.Com base na área superficial de captação da cobertura, foram utilizados 21 miniaspersores de baixa vazão (Naan-Dan Haddar 7110, bocal 1,8 mm de diâmetro e vazão nominal de $116 \mathrm{~L} \mathrm{~h}^{-1}$ ) para cada aviário. O espaçamento adotado entre os miniaspersores foi de 6,0 metros, os quais proporcionaram um diâmetro molhado de 8,5 metros, havendo, assim, uma sobreposição dos jactos de 2,5 metros, para promover uma uniformidade de molhamento na cobertura.Com isso, foi estimado que a necessidade de água para cada galpão seria de $2.436 \mathrm{~L} \mathrm{~h}^{-1}$, admitindo-se que as perdas seriam minimizadas com a recirculação da água, restringindo-se basicamente à evaporação.

No dimensionamento do reservatório para armazenamento de água da chuva, foram utilizados os dados das normais climatológicas de precipitação média do ano de 1961 a 1990 (BRASIL, 1992), correspondente a uma série histórica de 30 anos. Dessa forma, identificaram-se os meses com média de precipitação superior à média de evaporação (novembro a março) e os meses de maior média de evaporação, a qual foi determinada pelo evaporímetro de Pichê (julho a setembro). O dimensionamento do reservatório foi realizado para atender a demanda de água durante o período de maior estiagem, de maio a setembro. Para o abastecimento do reservatório, foram consideradas as médias das precipitações do período de novembro a março, que equivalem a $8,49 \mathrm{~mm} \mathrm{~d}^{-1}$. Com isso, o período estimado de utilização da água armazenada foi de 150 dias, que corresponde a 2,50 lotes de aves com peso médio ao abate de $2,70 \mathrm{~kg}$, admitindo-se o funcionamento do sistema no período compreendido entre o $21^{\circ}$ e o $42^{\circ}$ dia de vida das aves.

Para determinação da evaporação média do reservatório, durante os três meses de maior estiagem (junho a agosto), na região do município de Rio Verde (GO), considerou-se a perda de água por evaporação superficial de $5,5 \mathrm{~mm} \mathrm{~d}^{-1}$. Entretanto, apenas $10 \%$ deste valor foi considerado nos cálculos, pois o reservatório foi projetado para ser revestido com manta de polietileno de alta densidade e coberto com manta de PVC flexível cor preta e branca, com a face branca voltada para cima.

A água destinada aos bebedouros das aves foi renovada sete vezes ao dia, sendo que cada evento de renovação teve duração de 15 minutos e vazão de $15 \mathrm{~L} \mathrm{~min}^{-1}$. Desse modo, os efluentes dos bebedouros eram descartados no reservatório, sendo considerados nos cálculos como uma fonte de abastecimento, com uma vazão de $1.575 \mathrm{~L} \mathrm{~d}^{-1}$ por cada lote de aves. Este manejo de água dos bebedouros era importante para manter a água de bebida sempre fresca, sendo conhecido internacionalmente como flushing.

Para o dimensionamento do sistema de condução das águas pluviais até o reservatório, considerou

Nucleus, v.9, n.2, out.2012 
a utilização de calhas semicirculares de PVC com diâmetro interno de $100 \mathrm{~mm}$ e capacidade de transporte de $130 \mathrm{~L} \mathrm{~min}^{-1}$. As calhas foram instaladas em cada lateral dos galpões e dispostas de forma equidistante com declividade de $0,5 \%$, sendo então conectadas a três tubos verticais com diâmetro de $100 \mathrm{~mm}$. Finalmente, os tubos verticais foram conectados a uma caixa de pré-filtragem.

A caixa de pré-filtragem, constituída de concreto com dimensões de $0,6 \mathrm{~m}$ de profundidade, $1,0 \mathrm{~m}$ de largura e 2,0 m de comprimento, apresentava 50\% do seu volume preenchido com brita $\mathrm{n}^{\mathrm{o}} 3$. Este sistema de filtragem estava interligado ao reservatório por quatro tubos de $2 \mathrm{~m}$ de comprimento e $100 \mathrm{~mm}$ de diâmetro interno.

\section{Medição e instrumentação}

Os galpões foram monitorados continuamente do $21^{\circ}$ ao $42^{\circ}$ dia de vida das aves, sendo quantificadas as variáveis relacionadas ao ambiente térmico e mortalidade diária das aves. $\mathrm{O}$ ambiente térmico foi avaliado por meio da temperatura do ar $\left(\mathrm{T}_{\mathrm{bs}}\right)$, temperatura de globo negro $\left(\mathrm{T}_{\mathrm{gn}}\right)$, umidade relativa (UR) e velocidade do ar $\left(\mathrm{V}_{\mathrm{ar}}\right)$, sendo que as três primeiras foram obtidas por sensores/registradores (precisão de $\pm 1 \%$ ). A freqüência de aquisição de dados foi estabelecida a partir de leituras realizadas em intervalos de 15 minutos. A $\mathrm{T}_{\mathrm{gn}}$ foi medida por meio de sensores de temperatura introduzidos no interior de globos negros de plástico, pintados de preto foscos, os quais foram previamente calibrados em relação a um globo negro de cobre padrão. Os sensores/registradores foram instalados a 39 metros de distância dos exaustores e a 0,25 $\mathrm{m}$ de altura do piso. Para determinar a $\mathrm{V}_{\mathrm{ar}}$, foi utilizado um anemômetro de hélice digital $( \pm 3 \%)$ em intervalos de duas horas, sendo posicionado a $0,25 \mathrm{~m}$ de altura em relação à superfície da cama.

No ambiente externo, as variáveis meteorológicas ( $\mathrm{T}_{\mathrm{bs}}, \mathrm{T}_{\mathrm{gn}}$, UR e $\mathrm{V}_{\mathrm{ar}}$ ) foram mensuradas por um sensor/registrador (precisão de $\pm 1 \%$ ), o qual foi programado para realizar a aquisição de dados em intervalos de 15 minutos. Este sensor foi instalado no interior de um abrigo meteorológico, situado a 1,5 m de altura do solo. Os registradores externos foram sincronizados com os internos, visando a comparação posterior dos dados na escala de tempo.

Todos os sensores/registradores foram devidamente calibrados previamente no Laboratório de Instrumentação Agrometeorológica do Departamento de Engenharia Agrícola da Universidade Federal de Viçosa.

A partir dos dados meteorológicos obtidos em intervalos de $15 \mathrm{~min}$, foram calculados os valores horários do índice de temperatura de globo e umidade (ITGU), da carga térmica de radiação (CTR) e da entalpia específica do ar $(\mathrm{H})$, conforme as equações descritas a seguir.

O ITGU foi calculado por meio da equação proposta por Buffington et al. (1981):

$$
\mathrm{ITGU}=\mathrm{T}_{\mathrm{gn}}+0,36 \mathrm{~T}_{\mathrm{po}}+41,5
$$

Em que,

$\mathrm{T}_{\mathrm{gn}}$ é a temperatura do globo negro, ${ }^{\circ} \mathrm{C}$; e

$\mathrm{T}_{\text {po }}$ é a temperatura do ponto de orvalho, ${ }^{\circ} \mathrm{C}$.

A CTR foi determinada pela equação proposta por Kelly et al. (1954):

$$
C T R=0.100^{4} \cdot \sqrt[4]{2.51 \cdot \sqrt{V} \cdot\left(T_{g x}-T_{b g}\right)+\left(\frac{T_{g n}}{100}\right)^{4}}
$$

Em que, 
$\sigma$ é a constante de Stephan-Boltzmann, igual a $5,67 \times 10^{-8} \mathrm{~W} \mathrm{~m}^{-2} \mathrm{~K}^{-4}$;

$\mathrm{V}_{\mathrm{ar}}$ é a velocidade do ar, $\mathrm{m} \mathrm{s}^{-1}$;

$\mathrm{T}_{\mathrm{bs}}$ é a temperatura do bulbo seco, $\mathrm{K}$.

Segundo Barbosa Filho (2004), a entalpia específica do ar (H) tem sido proposta como o índice mais adequado para a avaliação do ambiente interno de galpões de criação de frangos de corte que, por definição, é uma variável física que indica a quantidade de energia contida em uma mistura de vapor d'água. A entalpia específica pode ser determinada como:

$$
\mathrm{H}=6,7+0,243 . \mathrm{T}_{\mathrm{bs}}+\left\{\frac{\mathrm{UH}}{100} \cdot 10^{\frac{7.5 \mathrm{~s}_{b s}}{237,3+\mathrm{T}_{\mathrm{bs}}}}\right\}
$$

Em que,

H é a entalpia, kj kg de ar $\mathrm{seco}^{-1}$; e

UR é a umidade relativa do ar, \%.

\section{Delineamento experimental e análise estatística}

O delineamento experimental foi inteiramente casualizado (DIC), constituído de dois tratamentos (técnicas de resfriamento) e três repetições (galpões).

A mortalidade diária das aves foi descrita por meio de um modelo linear generalizado misto. Considerou-se uma distribuição de Poisson para o número de aves mortas diariamente, com função logarítmica, sendo essa especificação considerada padrão para dados de contagem. Foram avaliados os efeitos do sistema de resfriamento (SRCS e SSA), da idade das aves e dos índices de conforto térmico externos (ITGU, CTR e H), bem como possíveis interações duplas entre essas variáveis.

Para isso, o efeito de cada galpão foi considerado como aleatório, com distribuição normal, para contabilizar as pequenas diferenças não controláveis/identificáveis em termos de ambiência e manejo existente entre galpões. Das variáveis externas, foi considerado o valor máximo diário para a modelagem da mortalidade.

As estimativas dos parâmetros foram obtidas pelo método da máxima verossimilhança via emprego da função glmmPQL do pacote de funções suplementares MASS do aplicativo do $\mathrm{R}^{\circledR}$. A avaliação da qualidade de ajustamento do modelo baseou-se na análise de resíduos.

\section{RESULTADOS E DISCUSSÃO}

\section{Dimensionamento do Sistema de Resfriamento de Cobertura Sustentável (SRCS)}

As variáveis consideradas no dimensionamento do reservatório necessário para o armazenamento da água proveniente da precipitação pluvial na estação chuvosa (novembro a março), para utilização posterior na estação seca (maio a setembro), estão apresentadas na Tabela 1. 
Tabela 1 - Variáveis utilizadas no dimensionamento do reservatório necessário para o armazenamento da precipitação pluvial durante a estação chuvosa (novembro a março)

\begin{tabular}{|c|c|c|}
\hline Variáveis & Qtd & Unid. \\
\hline Período de utilização do sistema & 150 & Dias \\
\hline Perdas diárias de água aspergida & 65 & $\%$ \\
\hline Evaporação média diária da região de Rio Verde & 5,5 & $\mathrm{Mm}$ \\
\hline Dias de utilização do sistema por lote & 21 & Dias \\
\hline Tempo diário de utilização do sistema (3 min ligado: 1,5 min desligado) & 4 & $\mathrm{~h} \mathrm{dia}^{-1}$ \\
\hline Quantidade de água aspergida por galpão & 2,436 & $\mathrm{~L} \mathrm{~h}^{-1}$ \\
\hline Água recuperada da aspersão & 852,6 & $\mathrm{~L} \mathrm{~h}^{-1}$ \\
\hline Água recuperada do flushing & 1,575 & $\mathrm{~L} \mathrm{dia}^{-1}$ \\
\hline Número de lotes & 2,51 & - \\
\hline
\end{tabular}

Em que,

$\mathrm{Q}_{\mathrm{a}}$ é a quantidade de água aspergida por hora por galpão $\left(\mathrm{L} \mathrm{h}^{-1}\right)$;

$\mathrm{R}_{\mathrm{c}}$ é a água recuperada da aspersão $\left(\mathrm{L} \mathrm{h}^{-1}\right)$;

$\mathrm{T}_{\mathrm{d}}$ é o Tempo diário de utilização do sistema (h);

$\mathrm{D}_{\mathrm{u}}$ é a quantidade de dias de utilização do sistema por lote;

$\mathrm{N}$ é o número de lotes;

L é a largura do reservatório (m);

$\mathrm{C}$ é o comprimento do reservatório $(\mathrm{m})$;

$\mathrm{E}_{\mathrm{v}}$ é a evaporação média da região $(\mathrm{mm})$;

$\mathrm{P}_{\mathrm{u}}$ é o período de utilização do sistema (dias);

$\mathrm{A}_{\mathrm{f}}$ é a água recuperada do flushing $\left(\mathrm{L} \mathrm{dia}^{-1}\right)$; e

$\mathrm{D}_{\mathrm{v}}$ é a quantidade de dias de vida das aves por lote.

O primeiro e o segundo termo da equação 4 correspondem, respectivamente, ao volume de água perdido pelo sistema de captação e volume de água evaporado no reservatório. Para a variável evaporação do reservatório, considerou-se $10 \%$ da evaporação média diária dos três meses de maior evaporação da região (junho a agosto).

Em relação ao período de manejo dos galpões de frangos de corte na região de Rio Verde-GO, verificou-se que, em termos médios para cada galpão, são criados 6,1 lotes durante o período anual. Considerou-se também que a necessidade de uso do sistema de aspersão sobre a cobertura será por um período de 21 dias por lote, ou seja, utiliza-se o sistema de resfriamento sempre a partir do $21^{\circ}$ dia de vida das aves.

No caso do sistema de aspersão, foi adotado o período de funcionamento compreendido entre 11:00 e 17:00 h, caracterizando-se assim, o período mais quente do dia, o que corresponde a um volume de água aspergida de $14.616 \mathrm{~L} \mathrm{dia}^{-1}$ galpão ${ }^{-1}$. Para reduzir o volume de água aspergida para $9.744 \mathrm{~L} \mathrm{dia}^{-}$ ${ }^{1}$ galpão $^{-1}$, considerou-se o controle dos intervalos de aspersão por meio de um temporizador programado para acionar o sistema a cada 3 minutos e desligá-lo após um período de 1,5 minutos.

Nucleus, v.9, n.2, out.2012 
Desse modo, foram realizadas simulações com base na alteração do diâmetro dos bocais e da utilização ou não do temporizador. Os resultados destas simulações estão apresentados na Tabela 2. Para isso, foram consideradas três opções de bocal, cobertura do reservatório ou exposição plena e sistema de acionamento com ou sem temporizador, totalizando 12 combinações.

Tabela 2.Simulação do volume necessário para o armazenamento da água proveniente da precipitação pluvial na estação chuvosa (novembro a março), para utilização posterior na estação seca (maio a setembro)

\begin{tabular}{ccccc}
\hline & \multicolumn{5}{c}{ Dimensões do reservatório } \\
\cline { 2 - 5 } & Largura (m) & Comprimento (m) & Profundidade (m) & Volume $\left(\mathrm{m}^{3}\right)$ \\
\hline \multicolumn{5}{c}{ Aspersor 1 } \\
\hline B & 11,50 & 33,34 & 3,50 & 1340,00 \\
B & 10,00 & 29,99 & 3,50 & 1049,00 \\
D & 9,50 & 24,70 & 3,50 & 821,00 \\
& 9,00 & 23,90 & 3,00 & 645,00 \\
\hline A & 11,00 & 28,38 & Aspersor 2 & 1092,00 \\
B & 11,00 & 26,00 & 3,50 & 858,00 \\
C & 11,00 & 20,99 & 3,00 & 692,00 \\
D & 9,00 & 19,08 & 3,00 & 515,00 \\
\hline & & & 3,50 & 776,00 \\
\hline A & 11,00 & 20,16 & 3,00 & 610,00 \\
B & 10,00 & 20,34 & 3,00 & 469,00 \\
C & 9,00 & 17,40 & 3,00 & 350,00 \\
D & 8,00 & 14,60 & &
\end{tabular}

Legenda: Aspersor 1 (bocal $2.0 \mathrm{~mm}$ vazão $138 \mathrm{~L} \mathrm{~h}^{-1}$ ); Aspersor 2 (bocal $1.8 \mathrm{~mm}$ vazão $116 \mathrm{~L} \mathrm{~h}^{-1}$ ); Aspersor 3 (bocal $1.6 \mathrm{~mm}$ vazão $88 \mathrm{~L} \mathrm{~h}^{-1}$ ); A (sem temporizador e sem cobertura); B (sem temporizador e com cobertura); C (com temporizador e sem cobertura); e D (com temporizador e com cobertura).

Com base nos resultados de simulação, as dimensões do reservatório selecionado foi 9,0 x 19,1 x 3,0 m, proporcionando um volume de armazenamento de água de 515,00 $\mathrm{m}^{3}$. Estas dimensões correspondem à área de superfície e a profundidade de um reservatório em forma de um paralelepípedo regular. Entretanto, na execução do projeto, devem-se considerar as características do solo e o tipo de máquina que vai realizar a escavação para determinar o ângulo de inclinação do talude.

O reservatório deve ser revestido com manta de polietileno de alta densidade e coberto com manta de PVC flexível cor preta e branca, com a face branca voltada para cima. A manta de cobertura deve ser fixada junto ao solo, com suas bordas enterradas para evitar a entrada da luz e possíveis fontes de contaminação. O local deverá ser cercado com tela de malha de duas polegadas e 1,8 $\mathrm{m}$ de altura para evitar a circulação de animais e pessoas próximos ao reservatório.

O sistema foi dimensionado para ser operado de forma independente do sistema de abastecimento de água dos bebedouros, devido às exigências de biossegurança do lote de frangos. O conjunto de moto bomba foi dimensionado para atender cada aviário independentemente, porém o reservatório foi 
dimensionado para armazenar a água de chuva coletada em dois galpões.

\section{Avaliação dos sistemas de climatização SRCS e SCC}

Pelo comportamento dos valores de ITGUs, CTR e H (Figura 1, Figura 2, Figura3, respectivamente) no interior dos galpões climatizados pelos sistemas SRCS e SCC, pode-se observar que, de maneira geral, o ambiente térmico não se mostrou homogêneo entre os galpões nos períodos mais quentes do dia (11:00h às 17:00h). Nessas figuras, foram adicionadas linhas que definem os limites inferior e superior de conforto térmico para frangos de corte que, no caso do ITGU, são estabelecidos pelos valores de 69,1 e 77,5, respectivamente (OLIVEIRA NETO et al., 2000; OLIVEIRA et al., 2006) e para H são de 64 e $70 \mathrm{kj} \mathrm{kg} \mathrm{de} \mathrm{ar} \mathrm{seco-1} \mathrm{(BARBOSA} \mathrm{FILHO,} \mathrm{2004).}$

Para o ITGU, o desconforto das aves ocorre em ambos os sistemas de resfriamento e ampliou-se durante o período mais quente do dia (10:00às 17:00h), devido, principalmente, à adição do efeito da radiação solar. Pode-se observar pela Figura1, que os galpões SCC apresentaram maiores valores de ITGUs que os galpões SRCS, sendo que no geral, os maiores valores encontrados ocorreram as 15:00h.Comportamento semelhante de ITGU foi observado em estudos realizados por Yanagi Jr. et al (2011), Damasceno et al. (2010), e Menegali (2009). Com isso, foi observado que a amplitude de variação do ITGU externo foi maior que a variação dos ITGUs internos aos galpões avaliados. Desse modo, podese afirmar que, dificilmente são conseguidos valores de ITGUs, considerados favoráveis ao desempenho produtivo das aves, em condições reais na produção avícola industrial, pois as instalações são abertas, não permitindo total controle, ficando sujeitas as variações climáticas externas.

Figura 1 - Variação horária do índice de temperatura de globo negro e umidade (ITGU) interno e externo aos galpões, ao nível das aves, durante o período de avaliação do Sistema de Resfriamento de Cobertura Sustentável (SRCS) e Sistema Convencional de Climatização (SCC).

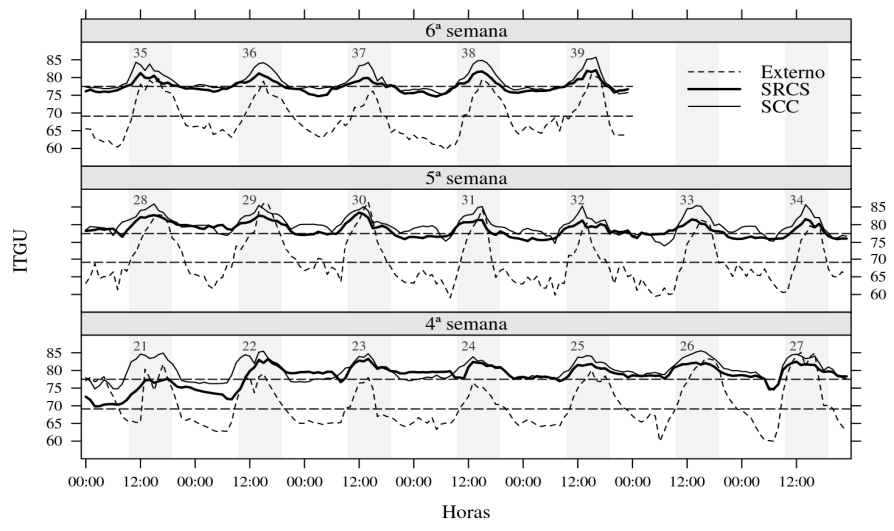

No caso da CTR (Figura 1) pode-se observar que os galpões SCC apresentaram nitidamente valores superiores aos encontrados nos galpões SRCS, principalmente nas horas mais quentes do dia, confirmando a depreciação do ambiente térmico devido à radiação solar excessiva. Nesta mesma figura, pode-se observar também que, a amplitude de variação externa foi maior que a interna aos galpões, sendo que o valor máximo observado ocorreu próximo das 14:00h. De acordo com Moraes (2002), valores de CTR acima de $450 \mathrm{~W} \mathrm{~m}^{-2}$ as aves apresentavam sintomas de estresse por calor. Desta forma, pode-se inferir que a aspersão sobre a cobertura contribuiu para que o galpão reduzisse a CTR ao nível das aves e, conseqüentemente, o estresse calórico dos mesmos. 
Figura 2 - Variação horária da carga térmica de radiação (CTR, em $\left.\mathrm{W} \mathrm{m}^{-2}\right)$ interna e externa aos galpões, ao nível das aves, durante o período de avaliação do Sistema de Resfriamento de Cobertura Sustentável (SRCS) e Sistema Convencional de Climatização (SCC).

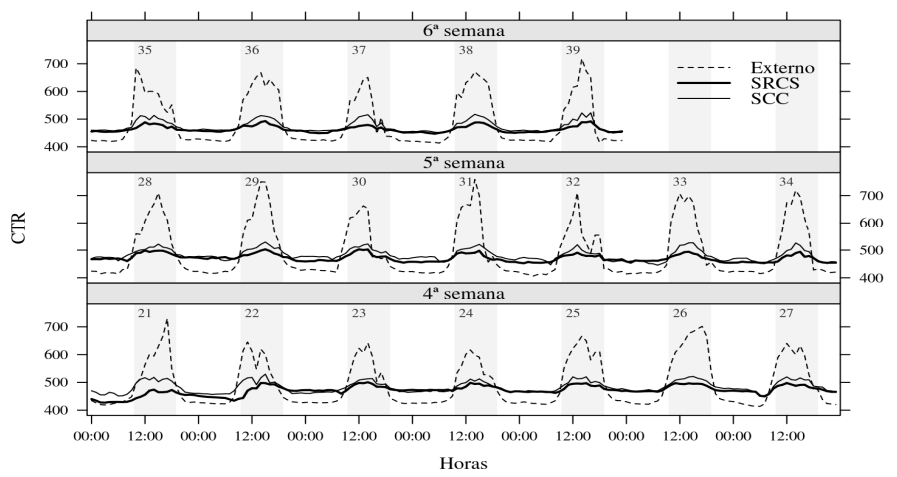

O comportamento de H (Figura 3) nos galpões, climatizados pelos sistemas SRCS e SCC, foi similar ao encontrado para o ITGU (Figura 2) e CTR (Figura 3), sendo que os valores médios apresentaram predominantemente acima do limite superior da faixa de conforto, principalmente nos períodos considerados mais quentes do dia. Comportamento semelhante de $\mathrm{H}$ foi observado por Damasceno et al. (2010), ao avaliar dois galpões avícolas com diferentes sistemas de resfriamento evaporativo do tipo placa porosa. As diferenças entre os sistemas de resfriamentos são mais nítidas no período quente, contudo, não sendo observada essa distinção de valores nos demais períodos do dia. Por meio da Figura 3, também pode-se observar que a amplitude de variação dos valores externos de $\mathrm{H}$ foi maior em relação aos valores internos.

Figura 3. Variação horária da entalpia específica do ar (H, em kj kg de ar seco-1) interna e externa aos galpões, ao nível das aves, durante o período de avaliação do Sistema de Resfriamento de Cobertura Sustentável (SRCS) e Sistema Convencional de Climatização (SCC).

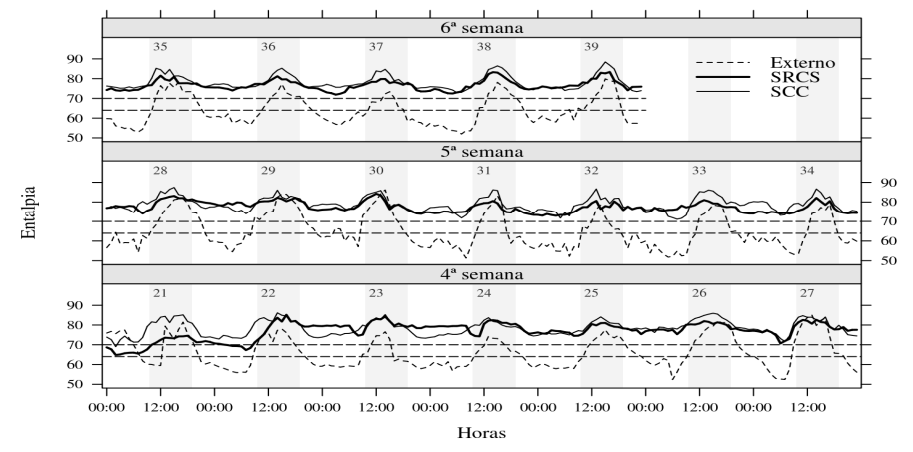

Com base nos valores máximos diários dos índices de conforto térmico (ITGU, CTR e H), efeitos de sistemas de resfriamento e idade das aves, ajustou-se os parâmetros de um modelo exponencial para a mortalidade diária das aves.

O modelo ajustado para ITGU, CTR e H apresentaram um desvio residual escalonado de 1,517, $1,622,1,495$, ou $0,917,0,913,0,918$ em termos do coeficiente de determinação obtido com o quadrado da correlação entre valores observados e valores preditos pelo modelo adotado ( $r^{2}$ ajustado), respectivamente. Independente do índice de conforto térmico utilizado no modelo, observou-se a ocorrência de superdispersão (desvio residual escalonado>1). Tal resultado pode ter ocorrido devido ao registro da mortalidade não ter sido realizado exatamente em intervalos de 24 horas, além de outras fontes de variação não identificáveis no presente trabalho. No entanto, para qualquer das variáveis ambientais 
externas consideradas, o valor do $\mathrm{r}^{2}$ ajustado foi superior a $90 \%$. Vale ressaltar que apenas o valor máximo diário das variáveis foi usado na modelagem, e não toda a série de valores diários. O diagnóstico dos resíduos apresentou padrões que apontam para uma adequada especificação do modelo ajustado.

De acordo com os valores dos desvios residuais escalonados encontrados, o modelo contendo o efeito da entalpia específica do ar $(\mathrm{H})$ apresentou menor dispersão $(1,495)$ e, portando, maior nível de explicação da variação observada $\left(r^{2}\right.$ ajustado $\left.=0,918\right)$. Para esse modelo, os efeitos principais do sistema de resfriamento utilizado (SRCS e SCC), idade das aves, bem como da interação entre sistema e H e entre $\mathrm{H}$ e idade ( Tabela 3) foram significativos. Dessa forma, o efeito dos sistemas de resfriamento sobre a mortalidade das aves é considerado dependente, tendo comportamento distinto, e não pode ser determinado sem prévio conhecimento da entalpia específica do ar máxima diária e da idade das aves, uma vez que esses fatores interagem entre si.

Tabela 3 - Teste de Wald para hipótese marginal de significância das fontes de variação consideradas no modelo com entalpia específica do ar $(\mathrm{H})$

\begin{tabular}{lcccc}
\hline F.V. & Fc & dfnum & dfden & p-valor \\
\hline Aspersão & 14,76245 & 1 & 4 & 0,0184 \\
Idade & 192,74220 & 1 & 104 & 0,0000 \\
Entalpia (H) & 0,81016 & 1 & 104 & 0,3702 \\
Aspersão x Idade & 62,54357 & 1 & 104 & 0,0000 \\
Aspersão x H & 6,33115 & 1 & 104 & 0,0134 \\
\hline
\end{tabular}

A mortalidade média no galpão SRCS não apresentou dependência da variação de $H$ ( $p=0,3702)$, o que indica que o sistema de resfriamento é eficiente, pois minimiza o efeito da variação de entalpia externa sobre a mortalidade das aves. Em outras palavras, o galpão SRCS apresentou uma menor mortalidade das aves devido à eficiência do sistema de resfriamento da cobertura proporcionar um ambiente interno menos estressante para os animais.

Por outro lado, a variação de H tem efeito sobre a mortalidade das aves sob o galpão SCC. Nesse galpão, é esperado um aumento de $3 \%\left(\mathrm{e}^{0,0297}\right)$ na mortalidade por unidade de acréscimo de entalpia ( Tabela 4 ), com os demais fatores inalterados.

Pode ser observado também que o aumento de idade das aves tem mais influência na mortalidade no galpão SCC em relação ao galpão SRCS, sendo esperado um aumento de $21 \%\left(\mathrm{e}^{0,193}\right)$ e $11 \%\left(\mathrm{e}^{0,107}\right)$ na mortalidade para cada dia a mais de vida, respectivamente, se for mantido os demais fatores do modelo constante.

O desvio padrão para o efeito do galpão foi de 0,124 (Tabela 4), o que reflete as diferenças entre os galpões em termos de condições térmicas ambientais sobre a mortalidade das aves.

Tabela 4 - Teste de significância para os coeficientes do modelo com entalpia $(\mathrm{H})$

(Continua)

\begin{tabular}{lccccc}
\hline Coeficiente & Estimativa & Erro padrão & DF & t-valor & p-valor \\
\hline SRCS & 0,48751 & 1,11468 & 4 & 0,43735 & 0,68440 \\
SCC & $-5,12841$ & 1,00795 & 4 & $-5,08797$ & 0,00700 \\
SRCS x Idade & 0,10710 & 0,00793 & 102 & 13,50273 & 0,00000 \\
SCC x Idade & 0,19274 & 0,00781 & 102 & 24,66749 & 0,00000 \\
SRCS x H & $-0,01100$ & 0,01257 & 102 & $-0,87542$ & 0,38340 \\
\hline
\end{tabular}


Tabela 4 - Teste de significância para os coeficientes do modelo com entalpia (H)

(Conclusão)

\begin{tabular}{lccccc}
\hline SCC x H & 0,02971 & 0,01090 & 102 & 2,72592 & 0,00750 \\
\hline Desvio padrão dos galpões & 0,123977 & & & & \\
Raiz do desvio escalonado residual & 1,222761 & & & & \\
\hline
\end{tabular}

Os valores obtidos pelo modelo de estimativa de mortalidade, a partir do $29^{\circ}$ dia de vida das aves para os sistemas de resfriamento SRCS e SCC, apresentaram intervalos de confiança não sobrepostos, sendo estatisticamente diferentes ( Figura 4). De forma geral, os galpões SCC e SRCS apresentaram uma mortalidade total de 683 e 384 aves por galpão, respectivamente, o que equivale dizer que a mortalidade no galpão SCC foi $77 \%$ maior que no galpão SRCS. A taxa de mortalidade total encontrada no galpão SCC foi de aproximadamente 3,0\%, enquanto que, para SRCS foi de 1,69\%. Os valores encontrados são inferiores ao citado pela Cobb-Vantress (2010) que foi de aproximadamente 5\% para a linhagem avaliada. Esta tendência de comportamento foi verificada por Damasceno et al. (2010), Furtado et al. (2003, 2006).

Por meio da Figura 4 é possível perceber que a variação da entalpia externa não provoca alterações no valor ajustado da mortalidade no galpão SRCS, mantendo os valores de mortalidade a uma taxa constante com aumento da idade. No entanto, para o galpão SCC, a variação da entalpia externa reflete na mortalidade das aves, além de que, a taxa de mortalidade éintensificada nos final do período produtivo.

Figura 4 - Variação da mortalidade diária das aves no período compreendido entre o $21^{\circ}$ e o $39^{\circ}$ dia de idade das aves (A), de acordo com o sistema de climatização adotado (SRCS e SCC) e valores máximos diários da entalpia específica do ar $(\mathrm{H}$, em $\mathrm{kJ} \mathrm{kg}$ de ar seco-1) (B). Os valores de $\mathrm{H}$ referem-se ao ambiente externo às instalações, obtidos no período correspondente, os quais foram usados para o ajuste dos parâmetros do modelo de estimativa da mortalidade. As linhas contínuas em (A) representam os valores estimados e as linhas tracejadas compreendem o intervalo de confiança (95\%).
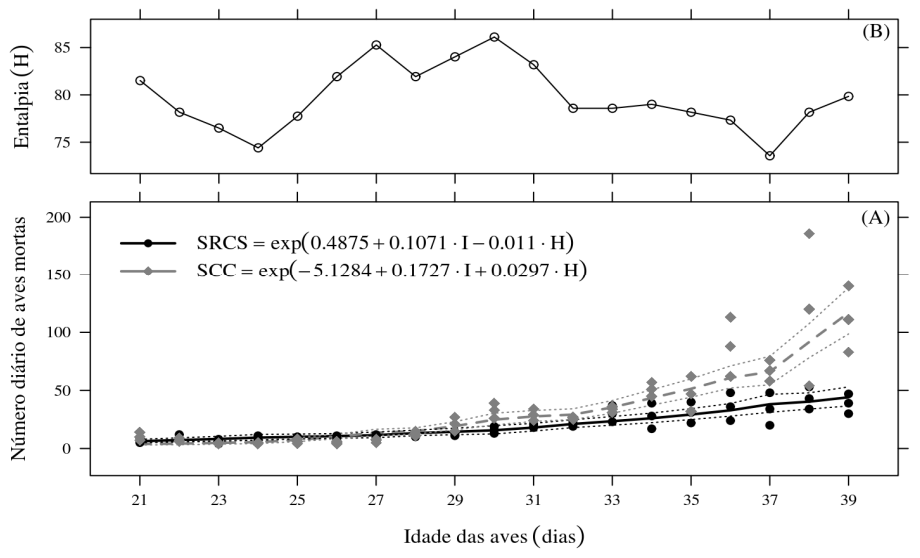

Nucleus, v.9, n.2, out.2012 
Tabela 5 - Parâmetros do modelo de mortalidade ajustado em função da idade e dos índices térmicos para ambos os sistemas de resfriamento

\begin{tabular}{|c|c|c|c|c|}
\hline \multicolumn{5}{|c|}{ Mortalidade de aves no SRCS e no SCC $=$ exp } \\
\hline Sistema & Índice Térmico Calculado & Parâmetro A & Parâmetro B & Parâmetro C \\
\hline \multirow{3}{*}{ SRCS } & ITGU & $\mathbf{0 , 5 5 3 7}$ & $\mathbf{0 , 1 0 7 3}$ & $-0,0117$ \\
\hline & CTR & $-0,2379$ & 0,1097 & $-0,0003$ \\
\hline & $\mathbf{H}$ & 0,4875 & 0,1071 & $-0,0110$ \\
\hline \multirow{3}{*}{ SCC } & ITGU & $-5,6194$ & 0,1936 & 0,0349 \\
\hline & CTR & $-3,6348$ & 0,1840 & 0,0017 \\
\hline & $\mathbf{H}$ & $-5,1284$ & $\mathbf{0 , 1 9 2 7}$ & $\mathbf{0 , 0 2 9 7}$ \\
\hline
\end{tabular}

Apesar da região onde se situavam os galpões avaliados possuir clima quente, principalmente no verão, o sistema de climatização convencional não foi capaz de garantir condições de conforto térmico ideal aos frangos de corte durante o período experimental. Entretanto, com a implementação do sistema de resfriamento adicional, a partir da aspersão de água da chuva armazenada previamente, contribuiu significativamente para redução da mortalidade das aves na última semana de vida ( Figura 4). Este resultado é de suma importância para o empresário rural, pois quanto maior for a idade das aves maior será o consumo de ração, mão de obra, medicamentos e insumos. Conseqüentemente implica em prejuízos financeiros, caso ocorra morte de animais por estresse calórico, principalmente, no final do período de crescimento.

\section{CONCLUSÃO}

Com base nos resultados encontrados, conclui-se que a aspersão de água, proveniente da chuva, sobre a cobertura da instalação permitiu a conservação e o reaproveitamento de água durante os períodos de acionamento do sistema, podendo ser considerado como uma ferramenta útil nas questões de sustentabilidade ambiental da criação de frangos de corte.

A mortalidade de frangos de corte pode ser estimada satisfatoriamente por meio do modelo exponencial que utiliza dados de entalpia específica do ar no ambiente externo e idade das aves após o $21^{\circ}$ dia, para instalações providas de sistemas de climatização convencional e sistemas convencionais com resfriamento adicional na cobertura.

\section{AGRADECIMENTOS}

Os autores agradecem ao CNPq, Capes, Fapemig e a Perdigão Agroindustrial S/A pelo suporte financeiro e ao Núcleo de Pesquisa em Engenharia de Sistemas Agroindustrial (AmbiAgro) pelo apoio técnico.

\section{REFERÊNCIAS}

ABREU, P. G.et al. Condições térmicas ambientais e desempenho de aves criadas em aviários com e sem o uso de forro. Arquivo Brasileiro de Medicina Veterinária e Zootecnia, Belo Horizonte, v.59 n.4, p.1014-1020, 2007. 
BARBOSA FILHO, J.A.D.et al. Egg quality in layers housed in different production systems and submitted to two environmental conditions. Brazilian Journal of Poultry Science, v.8, p.23-28, 2006.

BRASIL. Ministério da Agricultura. Normais climatológicas 1961-1990. Brasília, 1992. 84p.

BUFFINGTON, C.S.et al. Black globe humidity index (BGHI) as comfort equation for dairy cows. Transactions of the ASAE, v. 24, n. 3, p. 711-714, 1981.

COBB-VANTRESS. Ten-year success story for leading German producer. Technical Cobb Focus. Disponível em: <http://www.cobb-vantress.com>. Acesso em: 15 ago. 2010.

DAMASCENO, F. A.et al. Avaliação do bem-estar de frangos de corte em dois galpões comerciais climatizados. Ciência agrotecnologia, v. 34, p. 1031-1038, jul./ago., 2010.

FERREIRA JUNIOR, L. G.et al. Ambiente térmico no interior de modelos físicos de galpões avícolas equipados com câmaras de ventilação natural e artificial. Engenharia na Agricultura, v. 17, p. 166-178, 2009.

FURTADO D. A.et al. Efeitos de diferentes sistemas de acondicionamento ambiente sobre o desempenho produtivo de frangos de corte. Revista Brasileira de Engenharia Agrícola e Ambiental, Campina Grande, v.10, n.2, p.484-489, 2006.

FURTADO, D.A.; AZEVEDO, P.V.; TINÔCO, I.F.F. Análise do conforto térmico em galpões avícolas com diferentes sistemas de acondicionamento Revista Brasileira de Engenharia Agrícola e Ambiental, Campina Grande, v.7, n.3, p.559-564, 2003

KELLY, C. F.; BOND, T. E.; ITTNER, N. R. Designer of livestock shades. California Agriculture, v. 8, n. 8. p. $3-4,1954$.

MENEGALI,I.et al. Ambiente térmico e concentração de gases em instalações para frangos de corte no período de aquecimento. Revista Brasileira de Engenharia Agrícola e Ambiental, Campina Grande, v.13, p.984-990, 2009.

MORAES, S.R.P.et al. Conforto térmico em galpões avícolas, sob coberturas de cimento-amianto e suas diferentes associações. Revista Brasileira de Engenharia Agrícola e Ambiental, Campina Grande , v.3, n.1, p.89-92, 1999,

MORAES, S. R. P. Caracterização de sistemas de semiclimatização de ambiente, em galpões para frangos de corte, no sudoeste de Goiás. 2002. 148p.Tese (Doutorado em Engenharia Agrícola) Universidade Federal de Viçosa, MG.

NÄÄS, I. A.et al. Controle e sistematização em ambientes de produção. In: SILVA, I. J. O. (Ed.). Ambiência na produção de aves em clima tropical. Piracicaba: NUPEA - ESALQ/USP, v.1, p.75-148, 165p, 2001.

OLIVEIRA NETO, A. R.et al. Efeito da temperatura ambiente sobre o desempenho e caracteristica de carcaça de frangos de corte alimentados com dieta controlada e dois niveis de energia metabolizavel.

Revista Brasileira de Zootecnia, v. 29, n. 1, p. 183 - 190, 2000.

OLIVEIRA, G. A.et al. Efeito da temperatura ambiente sobre o desempenho e as características de carcaça de frangos de corte dos 22 aos 42 dias. Revista Brasileira de Zootecnia . v.35, n.4, p.1398-1405, 2006.

OLIVEIRA, R. F. M.et al. Efeitos da temperatura e da umidade relativa sobre o desempenho e o rendimento de cortes nobres de frangos de corte de 1 a 49 dias de idade Revista Brasileira de Zootecnia., v.35, n.3, p.797-803, 2006. 
PERDOMO, C. C. Mecanismos de aclimatação de frangos de corte como forma de reduzir a mortalidade no inverno e verão. In: Simpósio Internacional, sobre Instalações e Ambiência, 1988, São Paulo.

Anais...,São Paulo: FACTA, 1998. p.229-239.

SARTOR;V.et al. Sistemas de resfriamento evaporativo e o esempenho de frangos de corte. Scientia Agricola, v.58, n.1, p.17-20, jan./mar. 2001.

SEO, I. H.et al. Improvement of the ventilation system of a naturally ventilated broiler house in the cold season using computational simulations. Biosystems Engineering, v.104, n.1, p.106-117, 2009.

SIMMONS, J. D.; LOTT, B. D. Evaporative cooling performance resulting from changes in water temperature. Applied Engineering in Agriculture, v. 12, n. 4, p. 497-500, 1996.

TINÔCO, I. F. F.et al. Avaliação de materiais alternativos utilizados na confecção de placas porosas para sistemas de resfriamento adiabático evaporativo. Revista Brasileira de Engenharia Agrícola e Ambiental, Campina Grande,v.6, n.1, p.147-150, 2002.

USDA, UNITED STATES DEPARTMENT OF AGRICULTURE. Disponível em: $<$ http://www.usda.gov/wps/portal/usda > Acessado em: ago. 2010.

YANAGI JÚNIOR, T. et al. Caracterização espacial do ambiente termoacústico e de iluminância em galpão comercial para criação de frangos de corte. Engenharia Agrícola, Jaboticabal, v.31, n.1, p.1-12. 2011. 
Nucleus, v.9, n.2, out.2012 